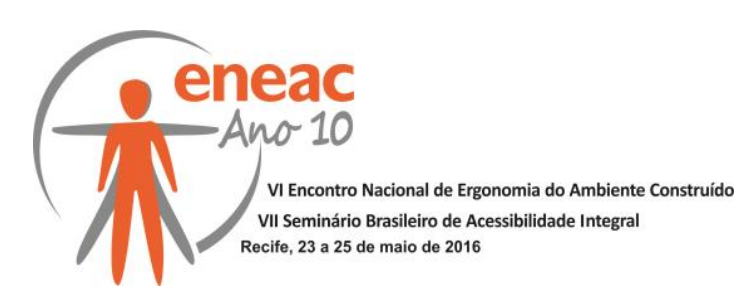

\title{
OS MAPAS TÁTEIS EM ESPAÇOS ABERTOS: UMA PROPOSTA DE INCLUSÃO SOCIAL NO PARQUE DA JAQUEIRA NO RECIFE-PE.
}

\author{
JORGE, Ester (1) \\ MACIEL, Ana Maria M. (2) \\ (1) FBV, Msc. em Desenvolvimento Urbano \\ e-mail:arq.estercosta@gmail.com \\ (2) UNINASSAU, Msc. em Gestão Pública \\ e-mail:anamariamaciel@yahoo.com.br
}

\begin{abstract}
RESUMO
Um espaço acessível e socialmente inclusivo deve garantir e oferecer as mesmas condições a seus usuários, independente de suas habilidades individuais. $\mathrm{O}$ deficiente visual necessita de estratégias e recursos diferenciados, possibilitando a locomoção com segurança e independência. Um dos recursos utilizados é o mapa tátil, que permite uma apreensão do espaço pelos deficientes visuais de maneira mais abrangente e didática. Neste sentido, este artigo propõe a inserção de um mapa tátil no denominado Parque da Jaqueira, com o intuito de proporcionar um uso mais efetivo por parte de seus usuários, possibilitando o conhecimento e o acesso com maior apropriação do espaço.
\end{abstract}

Palavras-chave: inclusão social, acessibilidade, deficiência visual e mapas táteis.

\begin{abstract}
An accessible space must ensure and offer the same conditions to its users, regardless of their individual abilities. The visually impaired need strategies and differentiating features, enabling mobility with security and independence. One of the resources used is tactile cartography, through tactile maps, which allow an apprehension of space by the visually impaired more comprehensive and didactic way. Thus, this paper proposes the insertion of a tactile map in a public space called Jaqueira Park, in order to enable more effective use by its members, to provide knowledge and access with greater ownership of space.
\end{abstract}

Key words: Social inclusion, accessibility, visual impairment and tactile maps.

\section{INTRODUÇÃO}

No Brasil, um dos principais direitos fundamentais, como o de ir e vir, não é alcançado pela maioria das pessoas portadoras de deficiência. Tornar um local acessível é promover condições de utilização com segurança e autonomia, independente de ser total ou assistida. Esta acessibilidade abrange espaços abertos, mobiliários e equipamentos urbanos, edificações, transportes, dispositivos, sistemas e meios de comunicação e informação.

Entre os portadores de deficiência, o deficiente visual, é o que mais sofre exclusão na ocupação e uso dos espaços da cidade, pois o sentido da visão é reconhecidamente o mais 


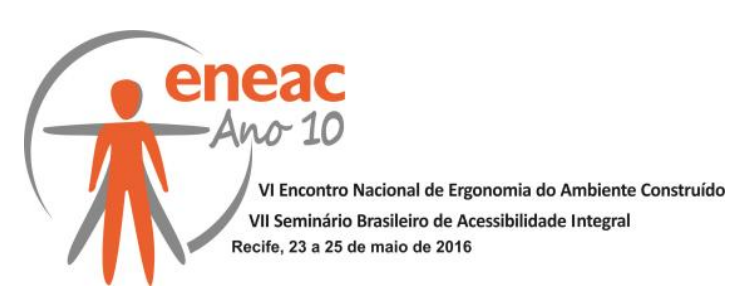

importante canal para a aquisição da informação espacial. Segundo Porter (2002) o deficiente visual sofre implicações psicológicas, como a irritação, stress e ansiedade, decorrentes de situações como aglomeração nas ruas e ambientes com ruído, provocando medo para se locomover.

Com o intuito de promover melhores condições para o deficiente visual ter uma acessibilidade efetiva, com condições de integração e apropriação nos espaços, são utilizados recursos e estratégias como os mapas táteis. Para Loch e Almeida (2008), os mapas táteis são representações gráficas em textura e relevo que servem para orientação e localização de lugares e fenômenos geográficos para os portadores de deficiência visual.

Utilizado como meio de informação espacial, o mapa tátil facilita a orientação e mobilidade. De acordo com Venturini (2007), esse recurso oferece condições para que os cegos formem esquemas espaciais de ambientes, antecipando suas decisões e minimizando a complexidade e pontualidade destes esquemas.

Para espaços abertos como os parques públicos, a utilização deste recurso amplia a possibilidade de uso por parte dos deficientes visuais e garante uma maior integração entre os usuários, promovendo, de fato, a inclusão social. Estes espaços funcionam como núcleos de atração, constituindo-se como locais de interatividade e sociabilidade dentro da cidade. Silva et al. (2007) enfatizam a importância desses espaços para o lazer contemplativo e à prática de esportes, o benefício como conforto térmico, conservação e conhecimento da biodiversidade, controle da poluição sonora e do ar.

Carneiro \& Mesquita (2000), descrevem a existência de oito parques urbanos em Recife. O Parque da Jaqueira, segundo Silva et al. (2007), é considerado um dos maiores e mais arborizados parques da cidade, com área de 7,0 ha. Neste sentido, este trabalho propõe a inserção de um mapa tátil no Parque da Jaqueira pela importância física e social, pois é o segundo maior parque da cidade e consegue atingir, nos fins de semana, uma frequência diária de até 6 mil visitantes.(LINS,2015).

\section{O PERCURSO METODOLÓGICO}

Para o desenvolvimento deste trabalho foi escolhida a pesquisa qualitativa, na tentativa de aproximar o pesquisador dos aspectos subjetivos que permeiam o universo do portador de deficiência visual. No desenvolvimento metodológico se configuram etapas teóricas e práticas, divididas em cinco fases: (1) Fase de estruturação teórica, é a construção do embasamento teórico, através do levantamento bibliográfico e documental do referencial teórico; (2) Fase de análise do espaço, com a observação in loco do pesquisador e de um portador de deficiência visual através do método do passeio acompanhado, assim como o levantamento iconográfico de fotos e mapas do espaço; (3) Fase de interpretação e confecção, neste momento será feita a análise dos dados e a confecção do protótipo do mapa tátil para teste posterior; (4) Fase de teste e adaptações, nesta fase os deficientes visuais utilizarão o mapa tátil e farão um passeio acompanhado para diagnosticar as vantagens e possíveis adaptações deste recurso; (5) Fase Conclusiva, onde serão feitas as considerações finais sobre o processo de construção deste trabalho. 


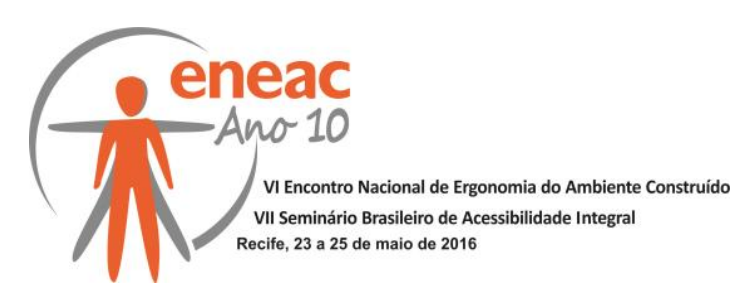

\section{O PERCURSO TEÓRICO E EMPÍRICO}

\subsection{Inclusão Social e Acessibilidade}

Em 1981, as concepções inerentes à inclusão social tiveram um forte avanço, através da declaração do Ano Internacional das Pessoas com Deficiência, pela a Organização das Nações Unidas e da Carta para os Anos 80, proclamada pela Rehabilitation International.

Para Holanda (1993. p.175), "incluir" significa: estar incluído ou compreendido, fazer parte. Assim, pode-se entender como inclusão social, a integração das pessoas deficientes na sociedade. Aceitar e valorizar a diversidade no âmbito social são ações que direcionam para uma sociedade inclusiva.

Segundo Sassaki (1997), a inclusão social é a forma pela qual a sociedade se adapta para poder incluir, em seus sistemas sociais gerais, pessoas com necessidades especiais e, simultaneamente, essas também se preparam para assumir seus papéis na sociedade.

Percebe-se que a inclusão social é um conceito que abrange a acessibilidade, e também pode ser considerado um objetivo desta. São dimensões diferentes, onde a inclusão social perpassa pela dimensão social e a acessibilidade se volta a dimensão do espaço.

A acessibilidade está em nosso cotidiano desde as pequenas atitudes, como a leitura de uma placa sinalizadora ou o simples alcance de uma alavanca. Está no conhecer e explorar de espaços naturais e edificados pelo homem, espaços públicos e privados, de pequena escala como os edifícios e de grande escala, a exemplo das cidades. A grande diferença está na maneira como a acessibilidade é permitida, devendo ser com independência e segurança por qualquer indivíduo, independente de suas limitações.

Foram necessários muitos anos de lutas e argumentações pelos deficientes e todas as pessoas que, de alguma forma, vivenciam e conhecem as dificuldades que permeiam 0 universo de um indivíduo que não consegue ter o direito de ir e vir atendido.

Em 1988, a Constituição Federal evolui neste sentido, referenciando em seu próprio título os direitos e garantias fundamentais, onde no art. $3^{\circ}$ define como objetivos: construir uma sociedade livre, justa e solidária; garantir o desenvolvimento nacional; erradicar a pobreza e a marginalização e reduzir as desigualdades sociais e regionais; promover o bem de todos, sem preconceitos de origem, raça, sexo, cor, idade e quaisquer outras formas de discriminação. (BRASIL, 1988).

Assim, é de interesse nacional a construção de uma sociedade igualitária, onde sejam estabelecidas prioridades embasadas na ausência de exclusão, independente das diversidades e limitações dos cidadãos.

A constituição federal ainda faz menção direta às pessoas com deficiência, garantindo, no art. 203: a habilitação e reabilitação das pessoas portadoras de deficiência e a promoção de sua integração à vida comunitária (BRASIL, 1988).

Para essa integração, a acessibilidade torna-se um pressuposto essencial, pois para alcançá-la deve-se ter um ambiente de condições mínimas para obtenção de informação/orientação sobre o espaço, permitindo a interação entre usuários, o deslocamento e uso dos equipamentos e mobiliários com segurança e conforto (DISCHINGER; BINS ELY; PIARDI, 2009).

Em 2000, houve mais um avanço no país, sendo instituída a Lei 10.098 que faz menção sobre a acessibilidade nos espaços públicos, incluindo pessoas com deficiência e mobilidade reduzida. Essa lei foi regulamentada pelo Decreto 5296 (2004), o qual define a acessibilidade como "condição para a utilização com segurança e autonomia, total ou assistida, dos espaços, mobiliários e equipamentos urbanos, das edificações, dos serviços 


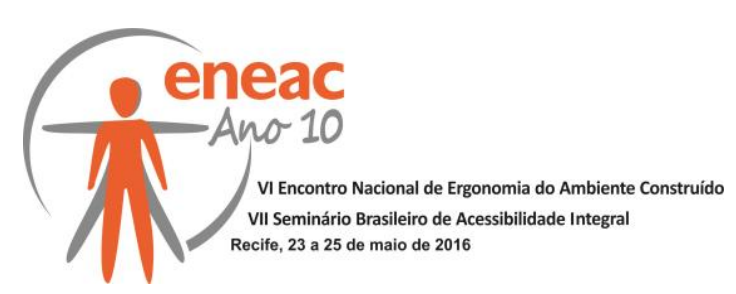

de transporte e dos dispositivos, sistemas e meios de comunicação e informação, por pessoa portadora de deficiência ou com mobilidade reduzida".

Para Bins Ely (2004), o alcance da acessibilidade depende da identificação de elementos que impeçam a percepção, cognição, circulação ou apropriação dos espaços e atividades por seus usuários, devendo ser considerados os obstáculos de ordem social e psicológica que prejudiquem a efetividade do uso destes espaços. Estes elementos são as barreiras, que ultrapassam os obstáculos físicos e, de acordo com Bins Ely et al I(2002), podem ser classificadas como: socioculturais, físicas e de informação.

As barreiras são elementos arquitetônicos ou de informação que prejudicam a obtenção de um dado desejado, com o intuito de se orientar no ambiente, dificultando assim, a capacidade de deslocamento. Podem ter um caráter temporário ou permanente, afetando o indivíduo em algum estágio da vida.

Assim, é necessário o uso de estratégias e recursos que diminuam essas barreiras, facilitando o acesso efetivo dos indivíduos, independente da existência de deficiências de qualquer ordem.

\subsection{Deficiência Visual}

Segundo dados do IBGE (2010), no Brasil, entre as deficiências investigadas, a deficiência visual apresenta a maior incidência, sendo declarada por $18,8 \%$ da população. Existem 45.606.048 de pessoas com algum tipo de deficiência. Onde se considera que 506.377 não enxergam de modo algum, 6.056.533 tem grande dificuldade, e 29.211.482 possuem alguma dificuldade para enxergar.

Para a delimitação do grupamento de deficientes visuais, cegos e portadores de visão subnormal, são analisadas duas escalas oftalmológicas: acuidade visual, aquilo que se enxerga a determinada distância e campo visual, a amplitude da área alcançada pela visão. Assim, pode-se definir os níveis de deficiência visual em: baixa visão moderada 20/80; baixa visão severa 20/200; baixa visão profunda 20/500; cegueira 20/1250; cegueira total na percepção da luz, quando uma pessoa é considerada cega.

No Brasil, se destacam três centros de âmbito nacional, O Instituto Benjamin Constant (1854), localizado no Rio de Janeiro, o Instituto Laramara(1991) e Fundação Dorina Nowill(1946), ambos em São Paulo. Estes centros apoiam a inclusão educacional e social, através da educação e profissionalização de crianças e adultos com deficiência visual. Em Recife, este apoio é dado através do Instituto dos Cegos Antônio Pessoa de Queiroz, fundado em 12 de Março de 1909, e considerado como o $2^{\circ}$ Instituto para cegos do Brasil e $01^{\circ}$ da região nordeste.

A deficiência visual limita, e algumas vezes, até impede algumas habilidades, fazendo com que o deficiente visual se sinta marginalizado e excluído de simples ações cotidianas. Esta situação, afeta o defciente e as pessoas que se relacionam com ele: familiares, amigos e outros. Para Rabasco: "[...] dependem muitas vezes da vontade e da ação de outros para ampliar progressivamente seu conhecimento do mundo. Sua educação na busca em conseguir uma autonomia está baseada em outorgar-Ihes as habilidades que Ihes permitam viver na sociedade que os rodeia e a compreender suas regras." (RABASCO, 2009, p. 406).

Para Veras e Vargas (2004), o deficiente visual, assim como as demais pessoas, passa por um processo sensorial e cognitivo, onde a recepção de informações a todo instante, Ihe permite reconhecer o universo ao seu redor e o capacita para a mobilidade. Contudo, a acuidade visual, resulta no aumenta do esforço cognitivo, fazendo com que o deficiente utilize recursos de memórias, representação espacial, tomada de decisões e outras habilidades que sobrecarregam o processo. 


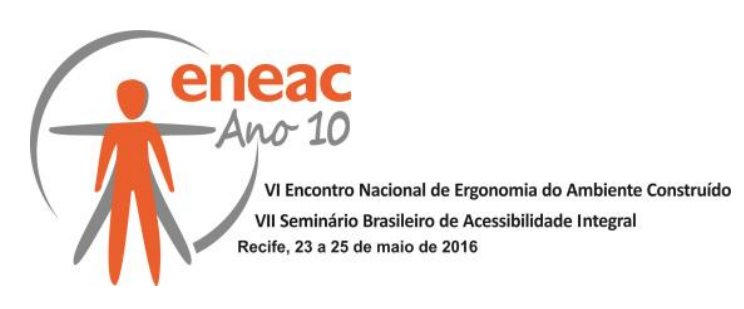

\subsection{A Cartografia Tátil}

Em 1837, na Perkins School for the blind, primeira escola para cegos dos EUA, Samuel Gridley Howe, adaptou todos os métodos de ensino para promover uma nova forma de aprendizagem. Howe inventou seu próprio sistema para a impressão e leitura e publicou 0 primeiro atlas tátil dos EUA.( McGINNITY et all, 2004).

Figura 1 - Mapas geográficos táteis, Instituto Perkins,South Boston, 1890.

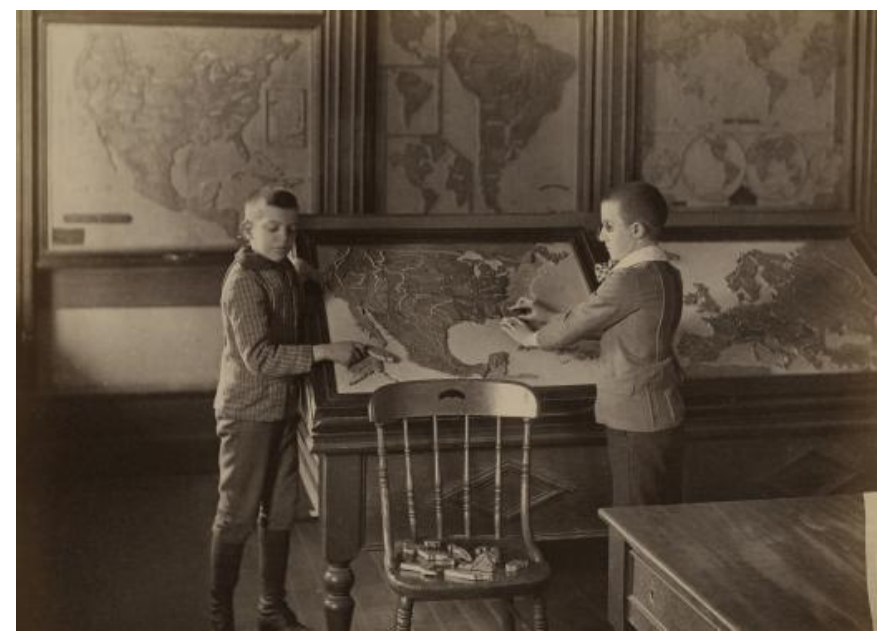

Fonte: Perkins (2015)

No Brasil, em 2006 foi criado o Laboratório de Cartografia Tátil e Escolar (LabTATE) na UFSC, um local que tem como objetivo a pesquisa e o projeto de extensão universitária voltados para a cartografia, geografia, cartografia tátil e demais temas que tenham ligação com a representação espacial.

Em Nogueira (2008), a Cartografia Tátil é definida como um ramo específico da cartografia, que se ocupa da confecção de mapas e outros produtos cartográficos que possam ser lidos por pessoas cegas e com baixa visão. Assim, os produtos resultantes desta cartografia, podem ser considerados como recursos da tecnologia assistiva, pois segundo Almeida e Loch (2005, p.41), a tecnologia assistiva é "todo o arsenal de recursos e serviços que contribuem para proporcionar ou ampliar habilidades funcionais de pessoas com restrições sensório-motoras e, consequentemente, promover vida independente e inclusão".

Para a confecção de uma mapa tátil, devem ser consideradas as variáveis gráficas que serão utlilizadas para a sua construção como: a textura, o tamanho, a forma e a altura. Fazendo a devida redução de escala para os fenômenos geográficos que podem ser representados por pontos, linhas e áreas. Para o deficiente visual, a decodificação através dos símbolos táteis e geográficos deve ser imediata. (LOCH ; ALMEIDA, 2008).

A elaboração de mapas táteis pode ser artesanal ou através de softwares. A primeira forma se inicia com o desenho dos mapas para a confecção da matriz e a colagem de diferentes materiais, como cortiça, emborrachados, barbantes e material de bijuteria. A segunda utiliza um software de desenho gráfico para imprimir o mapa convencional, o qual servirá como referência para o mapa tátil. Esta impressão é feita em materiais específicos, como papel microcapsulado, acetato ou braillon (LABTATE, 2008).

Deve-se ressaltar a importância do contraste de cores, para as pessoas com baixa visão em detrimento da diminuição da acuidade visual. Para Gomes Filho (2000), o contraste trabalha contra a tendência do equilíbrio absoluto, desequilibra, sacode, estimula e atrai a atenção. 


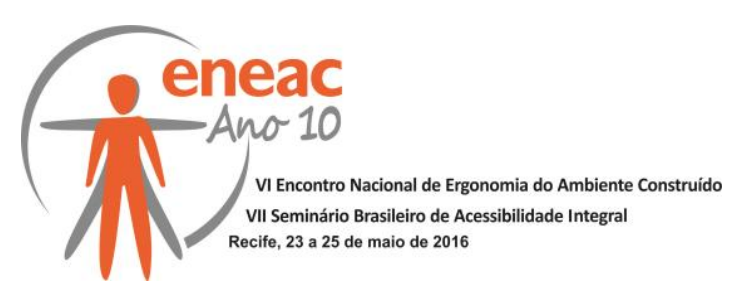

A utilização de mapas táteis perpassa pelo universo educacional e também para a orientação e mobilidade dos deficientes visuais. Estes precisam ser confeccionados em uma escala maior, pois devem conseguir abranger mapas de centros urbanos e ainda edifícios públicos com alta rotatividade de pessoas.

No âmbito internacional, a utilização de mapas táteis em parques urbanos já está sendo difundida há mais tempo. Como exemplos podem ser citados o Parque Guell, Parc de L' Estació Del Nord e Parc Del Centre Del Poblenou, todos situados em Barcelona (Figura 2).

\section{Figura 2 - Mapas táteis do Parque Guell,Parque del Centre Del Pobleou e Parque de L'estació Del Noro respectivamente.}
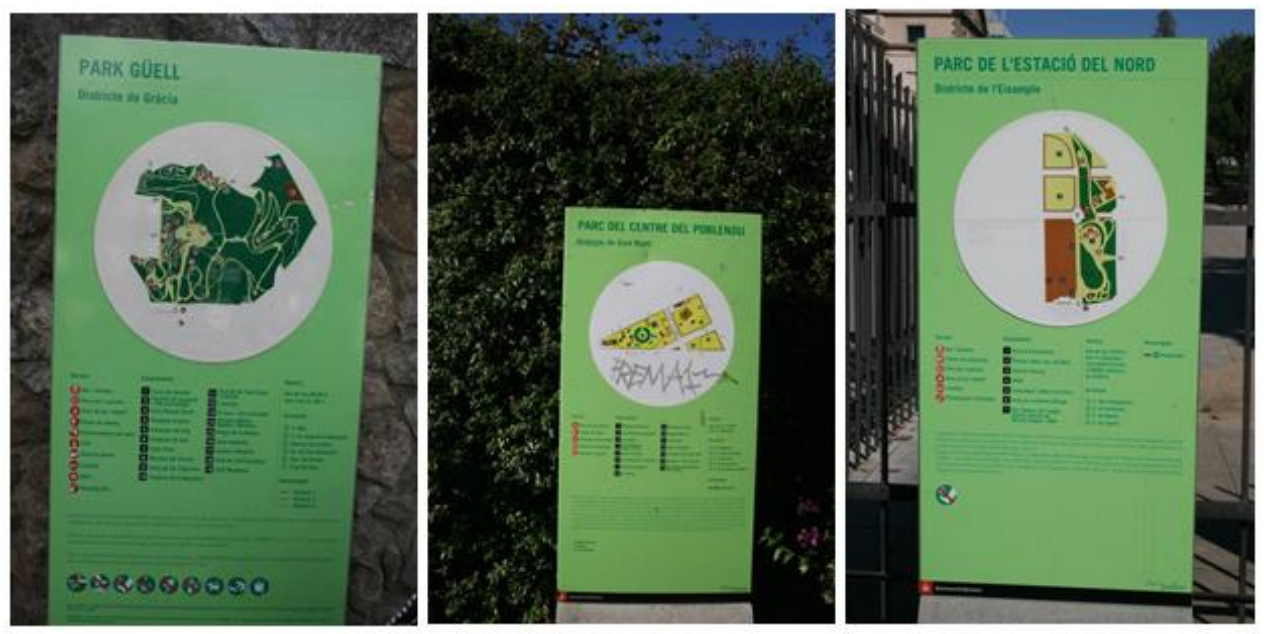

Fonte: Degreas(2016).

Nestes espaços, percebe-se uma padronização dos mapas táteis para os parques da cidade, os quais possuem contraste de cor adequado e apresentam também a localização dos ambientes dentro do parque. São confeccionados em metal e PVC com letras em alto relevo e braile, atendendo os deficientes visuais com baixa visual e acuidade visual zero. Estão localizados na entrada dos parques, permitindo um fácil acesso por parte dos usuários.

\section{ANÁLISES E RESULTADOS}

Conforme pesquisas realizadas por Queiroz (2010), as pessoas com deficiência visual são os menos contemplados em pesquisas sobre acessibilidade. Este trabalho propõe, portanto, o aprofundamento do estudo da acessibilidade de parques para pessoas com deficiência visual.

Para o desenvolvimento deste trabalho optou-se por uma abordagem qualitativa, pois se pretende identificar e estudar aspectos subjetivos. Para tanto, é necessário aprofundar-se nos "significados das ações e relações humanas, um lado não perceptível e não captável em equações, médias e estatísticas (MINAYO, 1993). Pretendeu-se compreender a percepção do espaço pelas pessoas com deficiência visual, suas relações com o ambiente, bem como identificar as restrições impostas por este ambiente, verificando a eficácia dos métodos e elementos atualmente empregados nos parques para possibilitar a acessibilidade para esse público-alvo. 


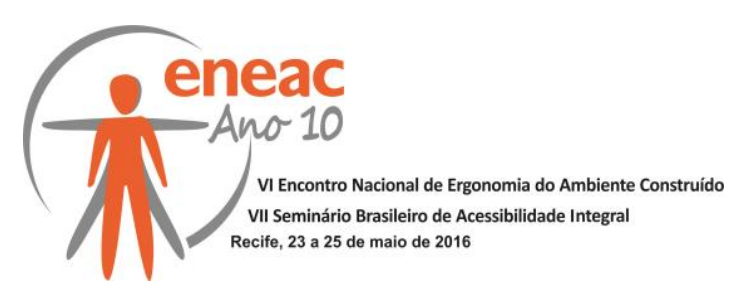

Procurou-se neste estudo, avaliar a aplicação e usabilidade de um mapa tátil no Parque da Jaqueira, em função da facilidade de acesso, diversidade das atividades disponíveis e dimensões.

$\mathrm{Na}$ experiência participaram 4 deficientes visuais, sendo 1 de nascença, e os demais com cegueira adquirida em função de patologias, selecionados a partir dos seguintes critérios: capacidade de deslocamento pela cidade com autonomia e independência; domínio do Braille e das técnicas de utilização da bengala, conhecimento ou não do Parque da Jaqueira.

Para garantir os aspectos éticos da realização destes passeios foi redigido um Termo de Autorização de Uso de Imagem e Depoimentos fornecido aos quatro participantes.

\subsection{A construção do Mapa Tátil}

O mapa tátil foi elaborado a partir da plotagem da UNIBASE municipal onde se pode identificar os elementos edificados, as rotas das pistas de pedestres, bicicletas e os diversos acessos presentes. Para a confecção foi utilizada uma base de papelão de alta densidade, revestido de EVA na cor vermelha, com as delimitações das pistas: branco, azul e amarelo, para diferenciar os usos ( cooper, skate e bicicletas).

Para a melhor compreensão tanto dos deficientes visuais de baixa visão, quanto dos de visão zero, foi acrescentado uma legenda em braille dos principais elementos edificados para facilitar a orientação dos futuros usuários (figura 3).

Figura 3- Construção do mapa tátil.

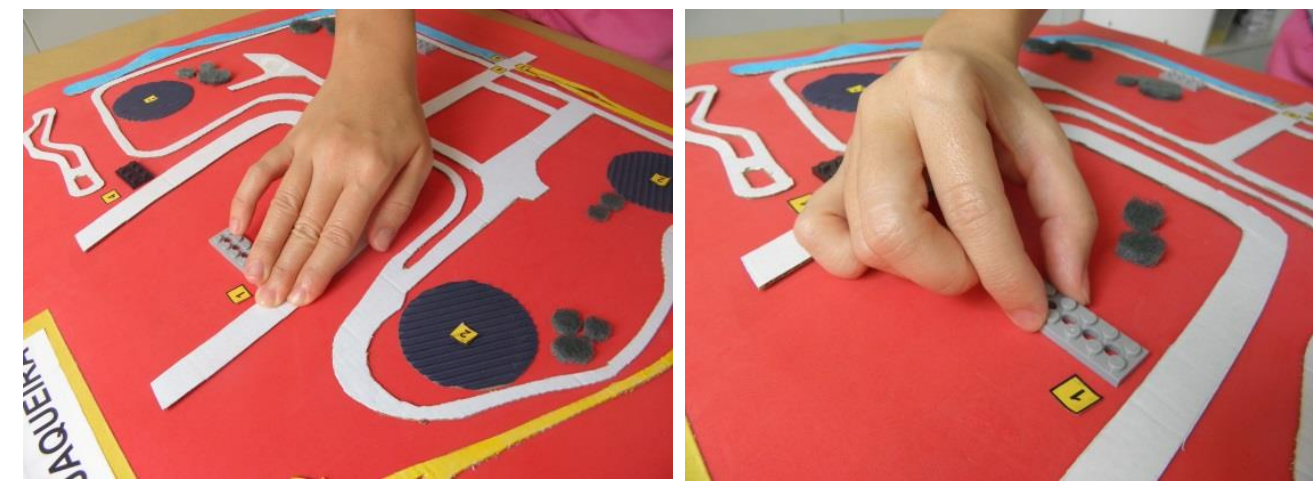

Fonte: Costa (2015)

\subsection{O Passeio Acompanhado}

Para Dischinger (2000), o passeio acompanhado é como uma visita realizada pelo sujeito que se pretende observar, acompanhado pelo pesquisador, por uma rota familiar ao participante, definida previamente, sem ser conduzido ou auxiliado, descrevendo detalhadamente as informações mais relevantes para o entendimento do espaço. Nesta pesquisa, o passeio acompanhado foi adaptado, visto que o trajeto foi acompanhado pelos pesquisadores (guias videntes), que, com informações verbais de localização e rota buscavam captar a aplicabilidade dos mapas táteis.

Em entrevista inicial, os entrevistados relataram nunca ter visitado o Parque da Jaqueira anteriormente, se disseram agradavelmente surpresos pela ambiência proporcionada (árvores, brisa, canto dos pássaros, entre outros) em plena área urbana. O passeio acompanhado foi realizado no período da tarde e durou em torno de três horas. Os 


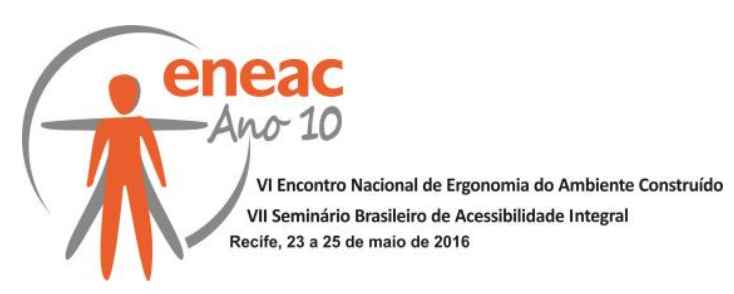

pesquisadores realizaram registros fotográficos, filmagens e anotações dos acontecimentos relevantes.

A seleção do Parque da Jaqueira como projeto piloto foi bem aceita em função do mesmo estar localizado às margens de um corredor viário de categoria urbano principal, bem servido por transporte coletivo e articulado a outras vias que conectam a região à zona central da cidade.

Embora sejam pessoas "independentes" em sua deficiência todos trabalham ou estudam. Demonstram serem atuantes em suas comunidades não conheciam o parque e não possuem o costume de frequentar áreas abertas e públicas, pois as mesmas não permitem seu uso com independência (autonomia).

Todos se mostraram disponíveis, pois destacaram a importância que a tecnologia assistiva para toda a comunidade de cegos, bem como a oportunidade de sensibilizar a sociedade pela causa da inclusão social.

\section{- 10 Passo}

Inicialmente, foi feita pelas pesquisadoras uma breve descrição da configuração espacial relacionando os principais elementos do parque, ou como denomina kevin Lynch (2008) os marcos da paisagem com a entrada principal por onde eles adentraram o parque;

\section{- 2o Passo}

Após a primeira aproximação do parque as pesquisadoras fizeram o reconhecimento tátil do mapa identificando os elementos físicos e as suas localizações em relação à pista de cooper/caminhada principal, elemento de reconhecimento/apropriação do parque(Figura 4).

\section{Figura 4 - A utilização do mapa pelos deficientes visuais}
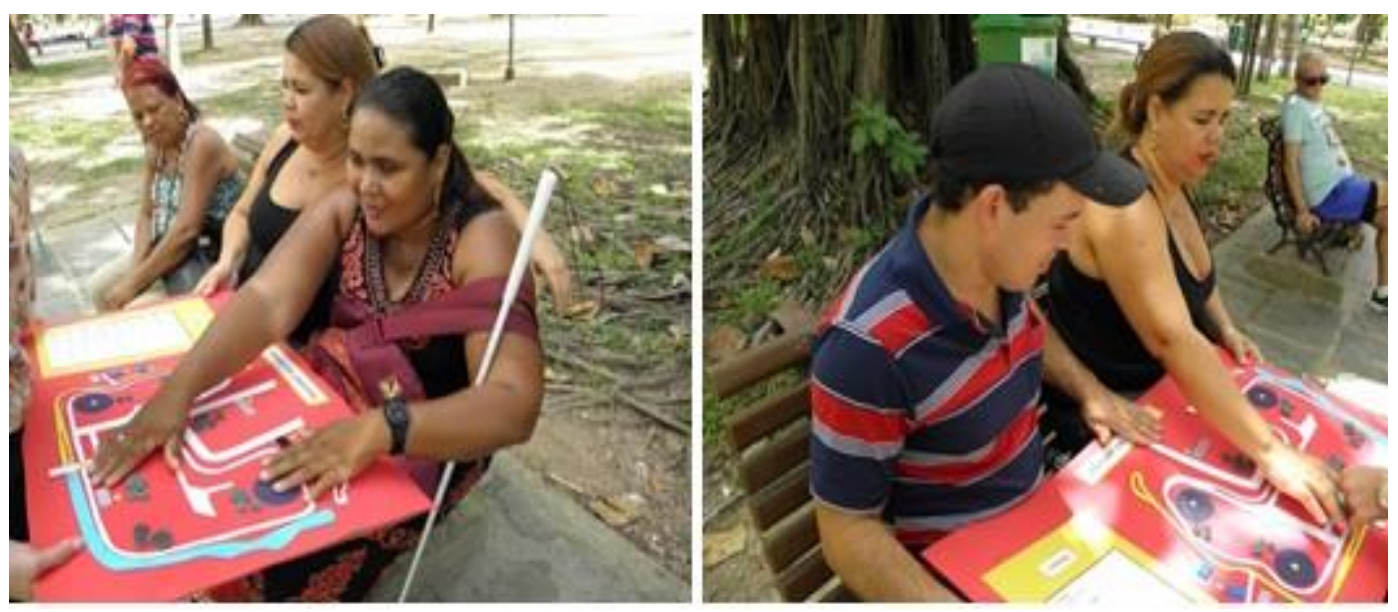

Fonte: Costa (2015)

\section{- 3o Passo}

Passeio acompanhado de todo o percurso da pista; reconhecimento e associação do trajeto real com o traçado do mapa tátil e relato das dificuldades/barreiras encontradas no trajeto (Figura 5). 


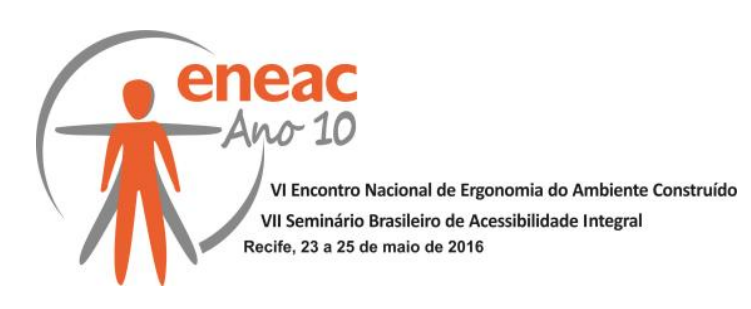

Figura 5 - 0 passeio acompanhado

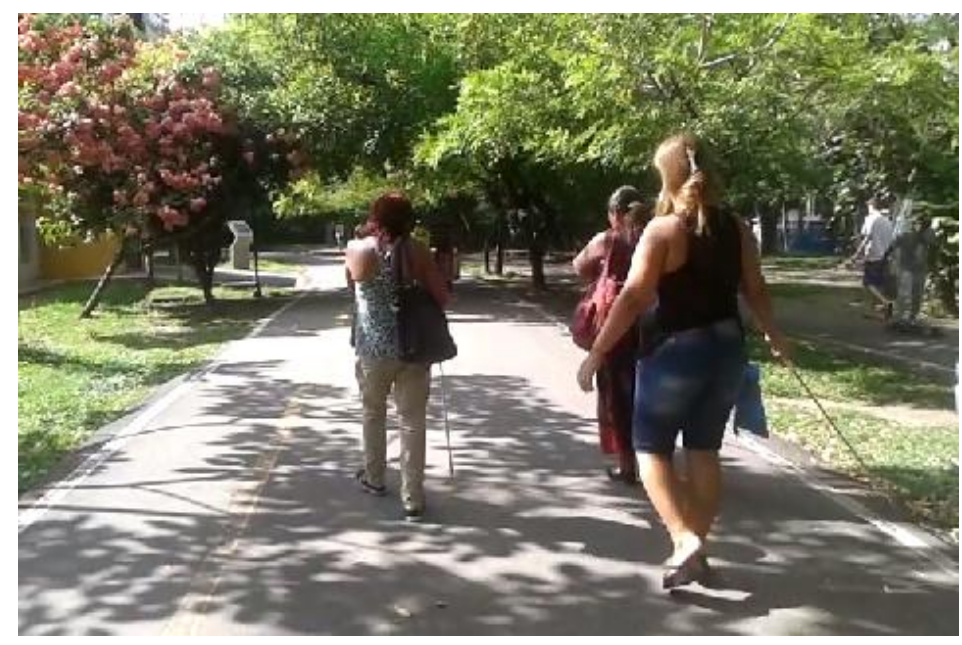

Fonte: Costa (2015)

\section{- 40 Passo}

Nesse passo foram identificados e definidos os ajustes/correções a serem agregados ao mapa tátil e de elementos a serem incorporados como:

- Demarcação das distâncias percorridas;

- Diferenciação de materiais nas pistas de cooper, skate/patinete, pistas de veículos;

- Demarcação de áreas perigosas, tais como: mobiliário, carrinhos de vendedores, bicicletas estacionadas, troncos de arvores, desníveis de meio-fio;

- Ausência de outros elementos promotores da acessibilidade e mobilidade como rotas acessíveis.

\subsection{ANÁLISE DO INSTRUMENTO - MAPA TÁTIL}

Os quatro deficientes visuais que participaram da pesquisa relataram que embora tenham tido pouco tempo para memorizar o parque e ser a primeira visita que realizavam a esse espaço, consideravam o instrumento extremamente válido. Consideraram que se o Parque da Jaqueira deveria contar com outros elementos promotores da acessibilidade como: piso tátil, rotas acessíveis e totens de sinalização tátil a independência seria total.

Três dos participantes manifestaram inclusive o desejo de repetir a experiência e sugeriram ampliar para as Praças do Derby e do Parque Treze de Maio.

\section{CONSIDERAÇÕES FINAIS}

É importante ressaltar a importância dos parques como espaços de lazer para pessoas com deficiência visual, e a atual falta de acessibilidade destes espaços. Normas e regulamentações são ignoradas, ou atendem pontualmente as exigências legais. Mas a acessibilidade deve ser pensada de forma mais ampla. 


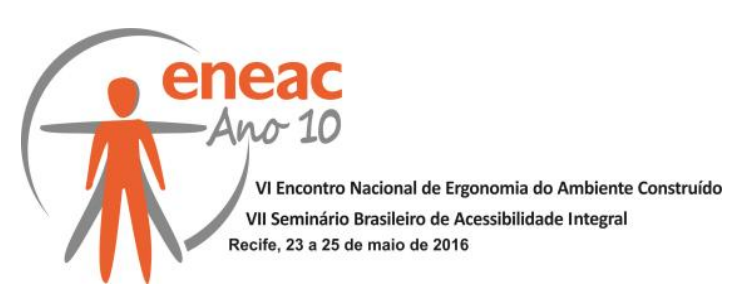

Criar acessibilidade e incluir as pessoas com deficiência é fundamental. E para compreender essas necessidades e propor alternativas para sua inclusão o profissional da ergonomia deve buscar alternativas junto a representantes desses grupos.

Propor tecnologia assistiva pressupõe lembrar sempre quem é nosso público alvo e qual as suas necessidades. Como afirma Porter (2000) a deficiência visual é a mais perturbadora, por não ver o que está em sua volta e desconhecer o que possa vir.

Neste trabalho foram mostradas imagens de outro país que já utilizam os mapas táteis, sabemos que muito ainda temos que fazer, mas, algumas já estão mostrando resultados.

Tornar acessível um espaço significa dotá-lo de sinalização e mobilidade, permitindo a todos os cidadãos deficientes ou não o direito de desfrutar uma vida decente, tão normal e plena quanto possível.

\section{REFERÊNCIAS BIBLIOGRÁFICAS}

ALMEIDA, L. C.; LOCH, R. N. Mapa tátil: passaporte para a inclusão. Extensio: Revista Eletrônica de Extensão, Florianópolis, v. 2, n.3, p. 3-36, dez. 2005. Disponível em: <http://www.extensio.ufsc.br>. Acesso em: 14 jul. 2010.

BINS ELY, V. H. M. Acessibilidade Espacial - Condição Necessária para o Projeto de Ambientes Inclusivos. In: DE MORAES, A. (Ed.). Ergodesign do Ambiente Construído e Habitado: Ambiente Urbano, Ambiente Público, Ambiente Laboral. Rio de Janeiro: iUsER, 2004.

BRASIL. Decreto n`5.296 de 2 de dezembro de 2004. Brasil,2004.

CARNEIRO, A. R. S.; MESQUITA, L. B. Espaços livres do Recife. Recife: Prefeitura da Cidade de Recife/Universidade Federal Rural de Pernambuco, 2000.

DEGREAS, Helena: https://mapatatil.wordpress.com. São Paulo, 2015.

DISCHINGER, M.; BINS ELY, V. H. M.; PIARDI, S. M. D. G. Promovendo a acessibilidade nos edifícios públicos: Programa de Acessibilidade às Pessoas com Deficiência ou Mobilidade Reduzida nas Edificações de Uso Público. Florianópolis: Ministério Público de Santa Catarina, 2009.

GOMES FILHO, João. Gestalt do objeto: sistema de leitura visual da forma. Escrituras, 2000.

LINS, Leticia. parque da jaqueira, o mais frequentado do recife, enfrenta assaltos. Disponível em: http://jc.ne10.uol.com.br/blogs/jcnasruas/2015/10/15/parque-da-jaqueira-o-mais-frequentado-dorecife-enfrenta-assaltos/.

http://www.perkins.org/history/legacy, 2005.

LYNCH, Kevin. A imagem da cidade. ed.70, Rio de Janeiro, 2008.

MCGINNITY,BL, SEYMOUR-FORD, J. e ANDRIES, KJ. Museu de História Perkins, Escola Perkins para Cegos, Watertown, MA.2004.

NOGUEIRA, Ruth Emilia. Cartografia Tátil. Disponível em: <http://www.labtate.ufsc.br.> Acesso em: Janeiro, 2016.

RABASCO, Francisco Pavón. Sociedad de la información y las personas ciegas. In: CASTELLANOS, Antonio Ruiz. et al. (org.). Prototipos: Lenguaje y representación em las personas ciegas. Cádiz: Universidad de Cádiz, 2009, p. 309-426

SASSAKI, Romeu Kazum: Inclusão: construindo uma sociedade para todos. Rio de Janeiro: WVA, 1997.

SILVA, L. R. L.; MEUNIER, I. M. J.; FREITAS, A. M. M. Riqueza de densidade de árvores, arvoretas e palmeiras em parques urbanos de Recife, Pernambuco, Brasil. Rev. SBAU, Piracicaba, v. 2, n.4, p.34 - 49, dez. 2007. 


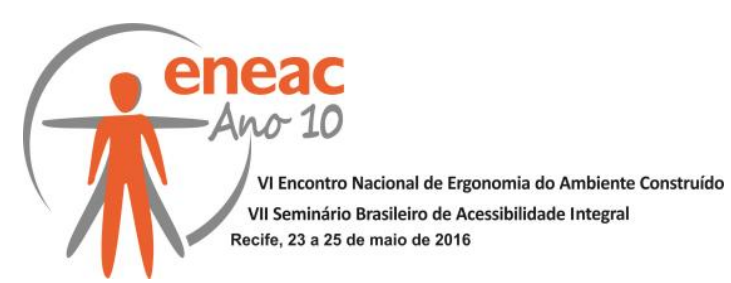

VERAS,L., C.S.VARGAS, O.L.DMREI: Sistema de ayuda a videntes para detectar el color y la posición de los objetos e diante estimulación táctil. VII Congresso lberoamericano de Informática Educativa. 2004. 